\title{
A ESCOLA PÚBLICA DE INSTRUÇÃO PRIMÁRIA BRASILEIRA. PROVÍNCIA DA PARAHYBA DO NORTE: 1822-1849
}

\author{
Cláudia Engler Cury ${ }^{1}$ \\ Mauricéia Ananias ${ }^{2}$
}

\section{RESUMO}

A narrativa de pesquisa sobre a história da escola pública de instrução primária tem a intenção de apresentar uma abordagem sobre o processo de escolarização ocorrido na Província da Parahyba do Norte entre os anos de 1822 a 1849. Para tanto, terá como mediação a análise acerca das propostas de instrução referenciadas como aulas, cadeiras, escolas de primeiras letras e/ou elementares decretadas pela legislação provincial e, oficialmente, oferecidas para uma parte da população livre. Para tal construção, a análise considerou que as relações de poder estabelecidas entre as ações do governo central, provincial e local foram fundamentais para compreender o processo de escolarização da Província paraibana. Os anos de 1835 a 1849 foram compreendidos como significativos para a organização e normatização da instrução pública primária, em especial com a promulgação das leis e dos dois regulamentos de 15 e 20 de janeiro de 1849. A perspectiva analítica utilizada optou pela compreensão geral de que as tentativas de criação e manutenção de um modelo organizado de instrução acompanharam os percalços da construção do Estado Nacional e das várias tentativas de constituição de uma identidade pátria para a Nação brasileira. Afirmamos, também, a iniciativa do governo provincial em instituir escolas de primeiras letras como parte da defesa de um projeto civilizatório para a redenção dos povos ignorantes.

Palavras- chave: Província; Paraíba; Escola pública; instrução primária.

\section{THE BRAZILIAN PRIMARY INSTRUCTION PUBLIC SCHOOL. NORTH PARAHYBA PROVINCE: 1822-1849}

\begin{abstract}
The research narrative about the history of the primary instruction public school intends to present a new approach about the schooling process occurred in North Parayba Province between the years 1822 and 1849. For such, it will have as mediation the analysis over the instruction proposals referenced as lectures, chairs, schools of first letters and/or elementary decreed by the provincial legislation and, officially, offered to a part of the free people. For such construction, the analysis considerate that the power relationships established between the central, provincial or local government actions were fundamental to understand o schooling process of the Parayba Province. The years between 1835 and 1849 were understood as significant to the organization and normalization of the primary public instruction, especially with the proclamation of the laws and regulations from $15^{\text {th }}$ to $20^{\text {th }}$ of January 1849 . The chosen analytical perspective opted for the overall understanding that the experiments of creation and maintenance of an instruction organized model follow the mishaps of the construction of National Estate and homeland identity to the Brazilian Nation. We also affirm the provincial government initiative on instituting schools of first letters as part of the defense of a civilizing project to the salvation of ignorant people. Keywords: Province, Paraíba; Public School; Primary instruction.
\end{abstract}




\section{Introdução}

Esta narrativa de pesquisa sobre a história da escola pública de instrução primária tem a intenção de apresentar uma abordagem sobre o processo de escolarização ocorrido na Província da Parahyba do Norte entre os anos de 1822 a 1849. Para tanto, terá como mediação a análise acerca das propostas de instrução pública primária referenciadas como aulas, cadeiras, escolas de primeiras letras e/ou elementares decretadas pela legislação provincial e, oficialmente, oferecidas para uma parte da população da então Província paraibana ${ }^{3}$.

A partir das ações do governo provincial, os anos de 1835 até 1849 foram compreendidos como significativos para a organização e normatização da instrução pública primária, em especial com a promulgação das leis e dos dois regulamentos de 15 e 20 de janeiro de 1849, fontes e objetos de análise dessa investigação. A perspectiva analítica utilizada optou pela compreensão geral de que as tentativas de criação e manutenção de um modelo organizado de instrução na então Província da Parahyba do Norte acompanharam os percalços da construção do Estado Nacional e dos vários ensaios de constituição de uma identidade pátria para a Nação brasileira desde os anos de 1822. Assim, retomar-se-á na análise os anos de 1822 até 1835 com a intenção de entender o processo de elaboração da primeira lei provincial na década de 1830; para, na sequência, examinar os anos até 1849.

Dessa forma, pretende-se trazer para a cena o processo de escolarização da Província por meio das ações que se pretendeu engendrar para a instrução pública primária a partir das propostas de normatização oficializada pelos governos provinciais utilizandonos de um lugar privilegiado: as próprias aulas públicas de primeiras letras.

Segundo Saviani (2005, p.25), a história da escola pública brasileira só poderá ser contada "instaurando-se um coletivo nacional de pesquisa que articule os esforços de estudiosos das diferentes regiões do país". A pesquisa apresentada se considera parte dos inúmeros empenhos para construção dessa tentativa. Para tanto, considerará os projetos nacionais acerca da reconstrução da escola pública numa relação proveitosa com a produção local que, ainda sem o escopo da síntese, será utilizada como componente basilar para abonar a importância dos esforços investigativos acerca da temática ${ }^{4}$.

Para tal construção, a análise problematizará a investigação considerando que as relações de poder estabelecidas entre as ações do governo central, provincial e local foram fundamentais para compreender o processo de escolarização da Província paraibana. De 1822 a 1833, a responsabilidade sobre a instrução primária era do Governo central, no entanto, a lei de 1828 prescreveu que a fiscalização das aulas de primeiras letras seria atribuição das câmaras municipais ${ }^{5}$. A reforma constituicional de 1834, através do Ato Adicional, conferiu, por interpretação, às províncias a responsabilidade em administrar a instrução primária e secundária criadas sob seu encargo ${ }^{6}$. Mais do que uma disputa de competências, a legislação será comprendida como mediadora da construção de um arranjo institucional de acomodamento das elites brasileiras para instituir as diversas esferas do Estado Nacional, inclusive a instrucional. (DOLHNIKOFF, 2005).

No caso da Província da Parahyba do Norte podemos destacar que os homens vinculados ao partido liberal ocuparam os principais cargos de direção do estado ao longo do século XIX e que o partido conservador manteve-se na oposição até a últimas décadas desse período, quando seus representantes conseguiram ocupar a presidência da Província. $\mathrm{Na}$ leitura da documentaço, principalmente nos jornais, percebeu-se que as propostas acerca da instrução pública veiculadas pelo partido liberal foram alvo de críticas por parte de seus opositores e que a pauta de sugestões para melhorias da instrução na Província foi constante nas páginas dos jornais assumidamente ligados ao partido conservador local. Os 
principais jornais, porta vozes dos dois partidos conservador e liberal, foram respectivamente o Jornal da Parahyba e o jornal Echo Escolástico.

Para a Parahyba do Norte, com a inauguração da Assembleia Legislativa provincial, em 1835, iniciou-se, dentre todas as demais, as atividades legais para a normatização da instrução primária. Tendo como base que a "autonomia deveria se concretizar no âmbito provincial e não na esfera municipal, de modo que os potentados locais fossem submetidos a uma elite política provincial comprometida com o Estado nacional [...]" DOLHNIKOFF, 2005, p.118-119), leis e regulamentos foram propostos, debatidos e aprovados. Para essa pesquisa, a partir da base documental, tentar-se-á apreender que a legislação para a instrução pública foi mediadora da construção do processo de escolarização de uma parte da população paraibana inserido no contexto de formação do Estado Nacional.

Para isso, utilizamos os regulamentos e as leis sobre a instrução pública primária a partir das Collecções das Leis Provinciais (1835-1889), publicadas, ordinariamente, em quase todos os anos após a criação das assembleias legislativas provinciais (PARAÍBA. PROVÍNCIA. Leis e regulamentos..., 2004); outro vasto conjunto de documentos, doravante denominados Documentos Diversos, sob a guarda do Arquivo Público do Estado da Paraíba, Waldemar Bispo Duarte, que discorre sobre o cotidiano administrativo desse universo legal para a instrução pública primária foi usado. Os relatórios dos presidentes da Província e seus respectivos relatos da instrução pública, hoje disponibilizados na rede mundial de computadores ${ }^{7}$, foram empregados não só para analisar os discursos sobre a instrução da época, mas, em especial, por serem uma fonte privilegiada para o entendimento entre o proclamado e o vivido, debate sempre pertinente aos estudos sobre o oitocentos, mas apenas serão considerados para os anos seguintes a 1837, primeiro ano de edição desse material na Província.

Aventou-se como problema que os diversos temas presentes nas leis menores, nas reformas e regulamentos, na maioria das vezes, eram objetos de pedidos, descontentamentos ou de reclamações dos próprios professores e das câmaras municipais que passavam aos deputados e, em última instância, aos presidentes da Província a responsabilidade de solucionar - por meio da elaboração de leis, ordens, ofícios e requerimentos, essas questões. Por outro lado, afirmar-se-á, também, a iniciativa do governo provincial em instituir escolas como espaços para o cumprimento da instrução elementar como parte da defesa de um projeto civilizatório para a redenção dos povos ignorantes.

Dessa forma, percebeu-se pela leitura e interpretação das fontes que as ações do Estado no campo da instrução pública foram constituídas não sem conflitos, mas, por meio de um arranjo entre o que era solicitado pelos professores, pelas câmaras municipais e a Assembleia Legislativa e o que era concedido pelo governo provincial numa dinâmica de atuação estatal que passava pela concepção da escola como redentora dos males sociais, pela necessidade de controle e formação dos professores e das aulas públicas.

Para a análise temática, compreendeu-se a legislação a partir do seu processo de elaboração. Para isso, foi cotejada com os requerimentos, ofícios, pedidos e orientações sobre a instrução inscritos nos Documentos Diversos numa perspectiva regressiva de decretação das leis. Dessa forma, para a primeira lei provincial de 1835 se considerou todos os documentos de 1822 a 1835 como significativos do processo de constituição da norma. Na mesma configuração, para os regulamentos de 1849, a produção de 1836 a 1849.

Considerando essa dinâmica, as leis foram compreendidas como construídas socialmente, e mediadoras, a partir dessas variadas intenções, das tentativas de construção de uma proposta de escolarização para uma parte da população. Também, para a 
construção da narrativa, foram utilizadas, em especial, as pesquisas e obras sobre a história da educação da Província paraibana, consideradas basilares no experimento de construção de um enredo possível de compreensão.

Para esta pesquisa, alertamos para um problema que se enfrentou, ou seja, construir, por meio das fontes, um sentido sequencial da criação das aulas. A documentação não forneceu dados seriais, seja por ano, localidade e/ou região, nomes e/ou dados dos professores e/ou alunos que possibilitassem o acompanhamento da criação, restauração, extinção e reestruturação das aulas, dificultando sobremaneira a tentativa de reconstruir a permanência e funcionamento das atividades destinadas à instrução primária nas aulas públicas. A existência desses espaços foi apresentada considerando as inferências realizadas a partir de dados dispersos em relação à criação de aulas pela legislação e informações fornecidas pelas câmaras municipais e/ou Assembleia Legislativa provincial que, muitas vezes, recebiam os pedidos, ofícios e requerimentos dos professores e/ou pais de alunos e supostas autoridades locais e os encaminhavam aos presidentes da Província, possibilitando, dessa forma, ao pesquisador contemporâneo apresentar mais uma defesa da legitimidade das criações das aulas, a partir da alegação da necessidade de escolarização de uma parte da população, do que uma regularidade do funcionamento desses espaços no tempo escolhido para análise.

Para atender a tais propósitos o texto, além da introdução, foi dividido em duas partes, mais as conclusões, que passamos a desenvolver a seguir.

\section{Entre as prescrições das leis e a efetivação da instrução pública primária na Província}

Para o ano de 1821, segundo Pinheiro (2002, p.18), havia na Província doze cadeiras de primeiras letras, duas na Capital e dez no interior destinadas ao sexo masculino.

Mesmo considerando as dificuldades enfrentadas pela Província nos anos próximos à independência política de Portugal e nos seguintes, esse mesmo autor citou, em 1825, a criação de mais cinco cadeiras em Bananeiras, Itabaiana, Santa Rita, Cabedelo e Serra da Raiz. (PINHEIRO, 2002, p.19 apud MELLO, 1956, p. 23-24). Para esse período, havia povoações e vilas mais próximas da capital já atendidas como Conde, Alhandra, Monte Mor, São Miguel e Pilar; outras na região da Serra da Borborema como Areia e Vila Nova da Rainha e também na região do Sertão paraibano- Pombal e Vila Nova de Souza.

Assim, numa visão geral, de acordo com esses autores, para os anos de 1783 a 1825, a Província tinha o seguinte quadro de aulas:

\begin{tabular}{|c|c|}
\hline ANOS & NÚMERO DE CADEIRAS \\
\hline $1783-1820$ & 2 \\
\hline \multicolumn{2}{|c|}{} \\
\hline 1821 & 12 \\
\hline 1825 & $12+5=17$ \\
\hline
\end{tabular}

Para os anos de 1821, 1822 e 1825, considerando uma possível demanda por aulas, e usando - sempre - a aproximação, pôde-se inferir, pelos pedidos de criações de algumas dessas aulas, que as câmaras municipais tinham a defesa da instrução como um dos elementos de ilustração da mocidade e desenvolvimento das povoações. Em novembro de 
1821, os vereadores da Villa de Pilar reclamavam da necessidade da criação de uma cadeira de primeiras letras. (PARAÍBA. PROVÍNCIA. Documentos Diversos... - Comarca do Pilar, 11 de setembro de 1821, paginação irregular).

A vereação da Villa Nova da Rainha, em nome da sua população, conclamava:

Os habitantes desta Villa, e de toda a compreensão do seu termo altamente persuadidos de que a ignorancia é o maior dos entraves, que há na vida humana, não só para em habituar os cidadão nos empregos públicos, como para estorvar qualquer duração feliz, que alguns indivíduos iluminados queiram dar a sua Pátria se não menos convencido de que Vossas Excelências, como administradores do governos civil e político desta Província, podem, querem, e devem querer fazer-lhes todo o bem possível, não hesitarão em recorrer a nós para fazermos a seguinte representação, como órgão que somos dos seus sentimentos. (PARAÍBA. PROVÍNCIA. Documentos Diversos... - Comarca de Campina, 1822, paginação irregular).

A defendida representação referia-se à necessidade de criação de uma cadeira de primeiras letras para a Vila justificando, além das contribuições de impostos pagas ao Tesouro Imperial, a existência de "[...] 40 meninos capazes de escolas sem fazer menção de outros muitos que já passam do tempo próprio, e julgam-se perdidos por falta dessa providencia”. (PARAÍBA. PROVÍNCIA. Documentos Diversos... - Comarca de Campina, 1822, paginação irregular).

Em 1825, a Câmara da Vila de Pilar, em correspondência enviada ao presidente da Província, avisava que a cadeira da Vila de Pilar estava provida, e que o mesmo não acontecia com a aula da povoação de Gurinhém ${ }^{8}$ que se encontrava vaga. (PARAÍBA. PROVÍNCIA. Documentos Diversos... - Vila do Pilar em vereação - 11 de maio de 1825, 1825, paginação irregular).

Para as aulas de meninas, a primeira referência encontrada diz da ordem de nomeação de uma professora:

Tendo sua Majestade o Imperador por Decreto da data de hoje, confirmando na cadeira de mestra de meninas da cidade da Paraíba do Norte, a Maria da Conceição Cabral, com o ordenado de trezentos mil réis. Manda pela Secretaria de Estado dos Negócios do Império participalo ao Vice Presidente da Província da Paraiba para sua inteligência, a expedição das ordens necessárias, depois que a referida mestra apresentar o citado Decreto (PARAÍBA. PROVÍNCIA. Documentos Diversos... Palácio do Rio de Janeiro em 18 de novembro de 1828/ Paraíba 9 de fevereiro de 1829, 1828, 1829, paginação irregular).

José Baptista de Mello (1956, p.24), confirma essa informação, dando conta de que "[...]. Foi instalada a escola na cidade de Nossa Senhora das Neves, e o nome de nossa primeira professora deve ficar registrado, para as homenagens de suas companheiras de profissão [...]. D. Maria da Conceição Cabral foi a primeira mestra que disseminou as primeiras luzes no rincão paraibano [...]" a partir da aprovação de um projeto encaminhado pelo conselheiro padre Joaquim Antonio Leitão de criação de uma escola para o sexo feminino em 18 de abril de 1828. (MELLO, 1956, p. 24).

A partir desses dados, deduz-se que para o ano de 1829 , considerando que a professora tenha apresentado o decreto às autoridades e assumido a cadeira, a Província contava com 18 cadeiras de primeiras letras, as 17 existentes mais a de meninas criada por 
ordem imperial.

Nos anos seguintes, pôde-se verificar, na documentação, a existência e o (mau?) funcionamento de algumas aulas. O professor da aula de Pombal foi acusado de "má conduta" pela Câmara Municipal. Segundo relato, as autoridades locais indicaram a punição, suspensão e a substituição por outro "de melhor moralidade e conduta". (PARAÍBA. PROVÍNCIA. Documentos Diversos... - Pombal em sessão extraordinária de 9 de dezembro de 1833, 1833, paginação irregular).

Há uma referência ao provimento de uma cadeira de primeiras letras pelo método mútuo em Serra da Raiz. A leitura do documento não permitiu afirmar se houve mais uma criação de aula nessa região ou se a aula já existente - de 1825 - foi reformada com a adoção do método proposto. A Câmara Municipal fez referência aos exames e aprovação, de acordo com a lei de 15 de outubro de 1827, do professor Padre Manoel de Carvalho e Silva. (PARAÍBA. PROVÍNCIA. Documentos Diversos... - Serra da Raiz, termo da Vila de São Miguel, 1833, paginação irregular).

Da mesma forma, a aula da Vila de Pilar foi citada, em 1834, como de ensino mútuo. O Juiz de Paz do Distrito de Gurinhém montou uma comissão para realizar uma "[...] avaliação dos utensílios mais necessários e indispensáveis para a aula do ensino mutuo das primeiras letras desta Povoação" como "bancos, banquinha, para cadeira do mestre" e "Taboa de operações" para a aula. (PARAÍBA. PROVÍNCIA. Documentos Diversos... - Palácio do Governo da Paraíba. 10 de julho de 1834, 1834, paginação irregular).

A Câmara da "Vila de Brejo de Areia em sessão extraordinária de 11 de junho de 1834", criticou,

[...] o desprezível estado em que se acha a aula de primeiras letras desta vila motivado pelo desleixo do professor da mesma José Francisco Marinho Falcão, que deixando de se empregar nas obrigações de que se acha encarregado para o ensino de seus alunos, entretem-se em passeios ilícitos, de sorte que tem com este procedimento feito ausentar os alunos que concorreram para o estudo, entrando-se proximamente um número muito diminuto [...]. (PARAÍBA. PROVÍNCIA. Documentos Diversos... - Vila de Brejo de Areia em sessão extraordinária de 11 de junho de 1834, 1834, paginação irregular).

A documentação indicou uma constância de reclamações das autoridades associando o mau funcionamento das escolas à postura dos professores das aulas públicas.

\section{A fiscalização, os métodos e os utensílios para as aulas de primeiras letras}

O mau - ou não - funcionamento das aulas também pôde ser percebido na cadeira de Piancó. Em 1834, a Câmara reclamou que o professor não "aparecia" para trabalhar desde dezembro do ano anterior. Outros documentos pediam materiais para a estruturação do funcionamento da aula, conforme requerimento abaixo. Uma comissão apresentou "Orçamento para o fabrico de aula do ensino mútuo Vila Constitucional de Santo Antonio de Piancó" que pleiteava verbas para:

Sessenta taboas as para as obras em geral, importando cada uma a importância $38 \$ 000$

Vem a ser as obras

Oito classes, contendo oito bancos, e oito lousas. Uma carteira. Uma taboa de operações de aritmética. Quatro moédas. Sete telégrafos. A cadeira do Professor. Tornos para chapear. Oito semicírculos com 
ponteiros e casas para os sustentar a 2500.

Madeira para os pés dos bancos, e mesa, e travejamento da cadeira e mais obra _. . [...]. (PARAÍBA. PROVÍNCIA. Documentos Diversos... Vila C. de Santo Antonio de Piancó. 9 de novembro de 1834, 1834, paginação irregular).

A aula de instrução primária da Vila de Piancó apareceu mais uma vez na legislação de 1835. Considerando todas essas informações, talvez, fosse provável que as aulas dessa cadeira, por falta de professor e materiais adequados, não funcionaram até o ano seguinte, pois a lei de $\mathrm{n}^{\circ} 116$ de 1835 prescreveu a criação de uma cadeira de primeiras letras para essa Vila. (PARAÍBA. PROVÍnCIA. Documentos Diversos... - Paço da Câmara Municipal da Vila de Piancó, em secção ordinária de 12 de março de 1834, 1834, paginação irregular).

O quadro abaixo, para o ano de 1834 , por aproximação, indica as seguintes aulas para a Província:

\begin{tabular}{|c|c|c|}
\hline \multirow{2}{*}{ ANO } & \multicolumn{2}{|c|}{ NÚMERO DE CADEIRAS } \\
\hline \multirow{2}{*}{1834} & Meninos & Meninas \\
\cline { 2 - 3 } & 18 & 01 \\
\hline
\end{tabular}

Para os anos seguintes, a mesma lei - de número 116 - de 19 de maio de 1835decretou a criação de mais 12 aulas de "primeiras letras". Desse montante, além da de Pilar, nos pareceu que a legislatura que propôs essas criações desconsiderou, também, a existência das aulas da Vila Nova de Souza, Vila Nova da Rainha (Campina Grande), São João e Pombal, ou as restabeleciam, ou criavam novas aulas para as mesmas regiões, pois essas se repetiram na nova lei, quais sejam, "[...] Ficam criadas aulas de primeiras letras nas povoações de São José, da Vila Nova de Souza, Catolé do Rocha, da de Pombal, Misericórdia, da de Piancó, Santa Luzia, Patos, Congo, da de S. João e de Boa Vista, da de Campina Grande [...]". (PARAÍBA. PROVÍNCIA. Leis e regulamentos..., 2004, p. 15, grifos nossos).

Pesquisas realizadas apontam os limites da interpretação dos dados; ao seguirmos as pistas deixadas pelos estudiosos da história da educação paraibana, encontramos mais problemas. Para essas escolas, "[...]. Não há notícias, contudo, de que as referidas aulas tenham sido todas providas com professores [...]”. (PINHEIRO, 2002, p.20, grifos no original).

No entanto, mesmo com todas as dificuldades de manutenção - e interpretação -, os registros apontam para a continuidade das criações de cadeiras. Na sequência, em 14 de março de 1836, a lei $\mathrm{n}^{\circ} 7$ criou "na povoação do Araçagi uma cadeira de primeiras letras de ensino vulgar". (PARAÍBA. PROVÍNCIA. Leis e regulamentos..., 2004, p.149). Para essa aula, em específico, não encontramos referências anteriores de existência.

Para esse mesmo ano, Joaquina de Fojos Correia foi examinada para assumir como professora de meninas da Vila de Areia. Desde 1821 encontramos referências da existência de uma aula para meninos nesse lugar. Em 1837, novamente a cadeira foi citada, a partir de um pedido de aumento de salário do seu professor (PARAÍBA. PROVÍNCIA. Documentos Diversos... - Vila de Areia, 26/janeiro de 1837, 1837, paginação irregular); o que indica a possibilidade da criação de mais uma cadeira, além da masculina, para o ensino das meninas. (PARAÍBA. PROVÍNCIA. Documentos Diversos... - Vila do Brejo de Areia em sessão ordinária de 12 de janeiro de 1836, 1836, paginação irregular). Ainda em 1837, mais uma lei foi votada. Não criava aulas, mas regulamentava-as, em especial, 
prescrevendo que os professores poderiam permutar suas cadeiras, bem como deveriam registrar todas as informações das suas aulas em livros. Anunciava que o Estado deveria fornecer não só o aluguel das salas como também a compra de "[...] bancos, e mesas, [...]." (PARAÍBA. PROVÍNCIA. Leis e regulamentos..., 2004, p.17).

Nesse momento houve o indicativo de que a fiscalização deveria ser feita pela presidência da Província: "As aulas da Capital serão fiscalizadas imediatamente pelo Presidente da Provincia ou por pessoa de sua confiança; e as outras por um inspetor nomeado pelo mesmo Presidente.[...]". (PARAÍBA. PROVÍNCIA. Leis e regulamentos..., 2004, p.18).

Até esse período, em geral, a legislação provincial ainda seguia a orientação de que a fiscalização das aulas elementares era responsabilidade das câmaras municipais, conforme indicava a legislação de 1828 . (BRASIL. Lei de $1^{\circ}$ de outubro de 1828,1986 ). A lei 116 de 1835 prescrevia que os atestados de frequência dos professores deveriam ser aprovados pelas câmaras e caso essas não pudessem se reunir, pelos juízes de paz da região. (PARAÍBA. PROVÍNCIA. Leis e regulamentos..., 2004, p. 15-16).

A agregação da competência das aulas à presidência da Província teve uma construção marcante nos anos finais da primeira metade do século XIX. Os próximos regulamentos confirmariam a defesa de que a organização da instrução, através da sua uniformização, deveria ser responsabilidade do governo provincial, justificando tal ação na necessidade de reformas a partir, inicialmente, do controle das aulas e professores. $\mathrm{O}$ estabelecimento de espaços para as aulas era parte dessa proposta.

O presidente da Província, João Antonio de Vasconcellos, em 1848, analisando os dados de 1847, apontou alguns problemas que mesmo "[...] a Instrucção publica primaria prosseguindo com regularidade" apresentava. Segundo ele, havia dificuldade em encontrar concorrentes habilitados para o trabalho de professor. Para esse ano, além das vinte em funcionamento, cinco cadeiras apareceram como à disposição para concurso. Também relatou a "[...] falta absoluta de livros de boa leitura nas escholas [...] Há também por falta nas Escholas de muitos utensílios: e alguns meninos por deficiência da família precizão de pennas, papel, tinta, \&c.,". (PARAÍBA. PROVÍNCIA. Discurso..., 1847, paginação irregular).

Talvez por essas dificuldades, os regulamentos promulgados em 1849 tiveram como base - para ordenar - um reduzido número de aulas, conforme indicado anteriormente nesse artigo em comparação com os anos anteriores.

$\mathrm{O}$ discurso de suas criações reconhecia todas essas dificuldades e anunciava a necessidade da uniformização das aulas como um dos caminhos para a resolução dos problemas da instrução primária do período.

Em virtude do artigo 30 da Lei n. 11 do anno passado, publiquei dous regulamentos, creando em hum delles a Directoria Geral da Instrucção Publica, e outro estabelecendo as regras para o ensino nas Escolas: sujeitei as escolas particulares à inspecção do Director Geral, e uniformisei por este modo o ensino. (PARAÍBA. PROVÍNCIA. Relatório..., 1849, paginação irregular).

A criação da Diretoria da instrução pública - e do cargo de diretor da instruçãodeveria atender ao enunciado da reforma que exaltava a falta de fiscalização sobre as aulas, os alunos e professores. Ao diretor caberia: "Inspecionar todo e qualquer estabelecimento de instrução, assim como todas as aulas públicas provinciais, ou seja, seus professores providos pelo governo, ou seja, particulares". (PARAÍBA. PROVÍNCIA. Leis e regulamentos..., 2004, p.20). Além disso, ficaria responsável por toda a regulação do 
"ensino público nacional" e deveria informar ao governo sobre a conduta dos empregados da instrução.

A legitimidade da autoridade também passava pelo fornecimento e controle dos dados da instrução. Ao assumir o cargo, o diretor ficaria responsável pela elaboração de um "relatório circunstanciado" que deveria ser enviado anualmente à Assembleia Legislativa provincial.

Em $1^{\circ}$ de agosto de 1849, o presidente da Província, apresentou o seu relatório de governo anunciando a criação dos regulamentos e do cargo. Na mesma ocasião afirmou a nomeação dos párocos "em quase todas" as freguesias como comissários da instrução. (PARAÍBA. PROVÍNCIA. Relatório..., 1849, paginação irregular).

Ainda no mesmo ano, o segundo regulamento "para as escolas de instrução primária" foi decretado. (PARAÍBA. PROVÍNCIA. Leis e regulamentos..., 2004, p. 21). A partir da defesa da precisão da uniformidade da instrução prescrevia, em tópicos, sobre o "local e mobília das aulas"; "disciplina"; "férias"; "recompensas"; "castigo"; "instrução moral e religiosa"; "estudos"; "leitura" e "escrita". Compondo esse conjunto geral, os artigos especificavam questões presentes no debate sobre a instrução da época. A recomendação do método a ser adotado - o simultâneo - aparecia no primeiro conjunto de itens ${ }^{9}$.

Indicado como o método mais moderno para as escolas, a propositura que o defendia anunciava as facilidades em se trabalhar com grupos de alunos com orientações de apenas um professor. Tempo e espaço economizados se comparados ao exemplo do ensino individual em que um único professor deveria atender a cada aluno separadamente. Reclamações do mau uso do tempo e da falta de organização das aulas contribuíram para a legislação instituísse o uso desse método.

Apesar de não ser uma novidade para a educação da época, pois há registros de seu uso nas escolas elementares europeias desde o final do século XVII, no Brasil - e na Paraíba - conviveu com a aplicação do método mútuo. (SOUZA, 2011, p.348). No conjunto seguinte de ordenações, havia a indicação de que o "professor escolherá dentre os alunos mais assíduos, inteligentes e de melhor conduta, alguns decuriões, que o ajudem nos diversos exercícios". (PARAÍBA. PROVÍNCIA. Leis e regulamentos..., 2004, p. 22). Essa mistura de orientações - tanto do ensino simultâneo, como do mútuo (e do individual que perpassou todo o período)- indicava o que foi caracterizado por método misto.

Para a Paraíba, estudiosos da história da educação já observaram essa situação.

Analisando os textos dos regulamentos de 1849, sobre os métodos de ensino, pode-se dizer que se tratava, na província da Parahyba, da utilização de um método misto. A organização das aulas e dos estudos, pela ótica dos legisladores, deveria realizar-se com a ajuda de decuriões ou monitores, mas a figura central da ação pedagógica era o professor. [...]. (CURY, 2006, p.50).

Souza (2011, p.350), apresentou um relato de um professor brasileiro que visitou escolas francesas de ensino simultâneo e que descreveu como elas deveriam funcionar. A forma indicava que para uma escola de "72 alunos" a turma deveria possuir cinco divisões e oito classes.

O regulamento recomendava que "toda a escola primária constará de 3 divisões principais, na razão da idade dos discípulos, e dos objetos de ensino, que os ocuparem" (PARAÍBA. PROVÍNCIA. Leis e regulamentos..., p.26). A divisão das aulas, significativa de sua organização, indicava as adaptações ao método prescrito e suas combinações com os já presentes nas escolas. 
Para o período, ao professor cabia não só a responsabilidade do controle interno das aulas, como também a garantia do local para realizá-las e a frequência dos alunos.

Essa carga sobre os nossos primeiros mestres, após a independência política, talvez nos ajude a entender as dificuldades de institucionalização da instrução elementar. Os professores faziam inúmeras queixas reclamando das condições para a realização dos seus trabalhos, da baixa remuneração recebida e das dificuldades em encontrar lugares salubres para as aulas. Quando encontravam, pleiteavam pagamento de aluguéis e de suas gratificações pela garantia da frequência dos alunos ${ }^{10}$.

As justificativas para o não atendimento dessas reivindicações, mesmo que reconhecidas, responsabilizavam as famílias como descuidadas com a educação e os professores como relapsos com a profissão.

Os pais de alunos eram vistos como "rústicos e ignorantes" e o professorado:

[...] ou pela natureza das suas funções, ou pelas diminutas vantagens, e poucas considerações, que geralmente tem, não é procurado senão por quem encontra dificuldades em alcançar meios de subsistência mais comodos e lucrativos e honorificos: sendo assim considerado antes como uma profissão honerosa e transcendentalmente importante $=\mathrm{D}^{\text {'isto }}$ resulta que o Professor sem vocação, sem estimulos nobres, sem compreender a sua missão, e a sua dignidade, limitar-se a satisfazer apenas aquela parte das suas obrigações, indispensável para dar-lhe direito ao ordenado; quando as satisfazem! = Espalhados por todos os lugares, ainda os mais remotos, e insignificantes, os Professores funcionam fora das vistas do seu chefe, longe do Centro de inspecção, que só seria capaz de imprimir-lhes zelo, e actividade. (PARAÍlBA. PROVÍNCIA. Documentos Diversos...- 1849, 1850, paginação irregular).

Os regulamentos prescreveram essa intenção de centralização das ações para a instrução primária na presidência da Província; os discursos tiveram como base a alegada rusticidade e ignorância dos pais para a defesa de um projeto civilizatório; da mesma forma, a falta de vocação e estímulos dos professores foi utilizada para justificar a fiscalização e a inspeção como solução dos problemas enfrentados caracterizando assim a proposta de escolarização da Província da Parahyba do Norte para esses anos finais da primeira metade do século XIX.

\section{Considerações finais}

No sentido de sistematizar algumas das questões que analisamos neste artigo reapresentamos a seguir dados acerca da movimentação da abertura e possível permanência das aulas para os anos iniciais da pesquisa. A partir de 1838, expomos dois quadros síntese com a intenção de mostrarmos a criação e a manutenção das escolas de primeiras letras como parte da nossa abordagem sobre a instrução pública primária.

Assim, para 1821 pudemos inferir que a Província contava com 12 cadeiras de instrução primária. Somando, em 1825, existiam 17 aulas espalhadas pelas diversas regiões da Paraíba.

Na sequência, considerando as lacunas entre os anos estudados, temos, para 1834, 18 aulas de meninos e 1 aula de meninas. 
Para 1838 até 1841:

\begin{tabular}{|c|c|}
\hline ANO & NÚMERO DE CADEIRAS \\
\hline \multirow{2}{*}{1838} & 45 \\
\cline { 2 - 2 } & Meninos 36/ meninas 9 \\
\hline \multirow{2}{*}{1839} & 45 \\
\cline { 2 - 2 } & Meninos 36/ meninas 9 \\
\hline \multirow{2}{*}{1841} & 46 \\
\cline { 2 - 2 } & Sem a divisão por sexo \\
\hline
\end{tabular}

Os dados indicaram que entre os anos de 1821 a 1834, ainda que o número fosse significativamente inferior aos anos vindouros, havia certa proporção na permanência dos números das aulas. Para os anos seguintes, um aumento do número de cadeiras manteve a regularidade para a década de 1840 . Essas afirmações, além da citação de criação nas leis e nos comentários encontrados nos Documentos Diversos, também foram mencionadas nos relatórios dos presidentes da Província indicando para os pesquisadores a possível existência das referidas aulas. Para esses últimos, apenas as "cadeiras abertas", portanto, com o pressuposto dos seus funcionamentos, foram contabilizadas para este estudo.

Para os anos seguintes:

\begin{tabular}{|c|c|}
\hline ANO & NÚMERO DE CADEIRAS \\
\hline \multirow{2}{*}{1843} & 26 \\
\hline \multirow{2}{*}{1847} & Meninos 19/ meninas 2 \\
\hline \multirow{2}{*}{1848} & Meninos 17/ meninas 3 \\
\cline { 2 - 2 } & 26 \\
\cline { 2 - 2 } & Meninos 23/ meninas 3 \\
\hline
\end{tabular}

Pudemos perceber certa redução, para os anos de 1846 e 1847, que inferimos que poderia ser explicada, em parte, pela supressão das cadeiras do Conde, Serra da Raiz, Guarabira e Bananeiras. (PARAÍBA. PROVÍNCIA. Leis e regulamentos..., 2004, p.150).

A restauração das aulas de Santa Rita, Itabaiana e Areia - sexo feminino (PARAÍBA. PROVÍNCIA. Leis e regulamentos..., 2004, p. 150) e da criação, em 1848, em Cabedelo (PARAÍBA. PROVÍNCIA. Leis e regulamentos..., 2004, p.150); Boa Vista (PARAÍBA. PROVÍNCIA. Leis e regulamentos..., 2004, p. 16), Barra de Natuba, Pitimbu, Freguesia de Jacoca (PARAÍBA. PROVÍNCIA. Leis e regulamentos..., 2004, p.151) elucidam, também parcialmente, a pequena retomada registrada em 1848.

Há ainda uma última questão que identificamos nos documentos e na historiografia consultados na direção de um esforço das autoridades provinciais e da Corte em implementar a regularidade e uniformidade no oferecimento de cadeiras de primeiras letras. Trata-se do debate sobre a obrigatoriedade do ensino e suas articulações com o projeto de construção de uma educação nacional no século XIX, conforme discutido em Pinheiro (2013). O autor identificou um documento de 1849 que, embora não se possa garantir que tenha sido o primeiro a ser elaborado sobre o tema em terras paraibanas, trazia as orientações do então presidente da Província João Antonio de Vasconcelos, um homem ligado ao partido liberal, acerca da importância da obrigatoriedade do ensino: 
Era para se desejar que essa uniformidade fosse em todo o Império para que estabelecesse melhor a nacionalidade pela identidade de ideas e de sentimentos entre todos os cidadãos, como se fossem uma família.(VASCONCELOS, 1849 apud PINHEIRO, 2013, p. 174).

Da mesma forma, a defesa da elaboração dos regulamentos de 1849 indicou a orientação de uniformização e centralização da instrução pública sob os cuidados diretos da presidência da Província.

Considerando os dados apresentados e as análises propostas, entregamos aos leitores os primeiros ensaios relativos à sistematização da escolarização da instrução pública primária na Província da Parahyba do Norte cobrindo a primeira metade do século XIX por meio da documentação coletada ao longo da última década, articulada com as reflexões com a historiografia paraibana que vem se debruçando sobre essa e outras temáticas no campo da história da educação brasileira.

\section{Referências}

BRASIL. Lei de $1^{\circ}$ de outubro de 1828. In: Constituições do Brasil de: 1824, 1891, 1934, 1937, 1946 e 1967 e suas alterações. Índice ALENCAR, A. V. N. de; RANGEL, L.C.B. Brasília: Senado Federal, subcretaria de Edições Técnicas, 1986, p.37-46.

BRASIL. Lei ${ }^{\circ}$ 16, de 12 de agosto de 1834. In: Constituições do Brasil de: 1824, 1891, 1934, 1937, 1946 e 1967 e suas alterações. Índice ALENCAR, A. V. N. de; RANGEL, L.C.B. Brasília: Senado Federal, subcretaria de Edições Técnicas, 1986, p. 49-53.

CURY, C.E. Métodos de ensino e formas de controle sobre o cotidiano escolar na instrução pública da Parahyba do Norte. In: SCOCUGLIA,A.C.; MACHADO, C.J. dos S. (Orgs.). Pesquisa e historiografia da educação brasileira. Campinas, SP: Autores Associados, 2006, p. 41-61.

DOLHNIKOFF, M. O pacto imperial. Origens do federalismo no Brasil do século XIX. São Paulo: Globo, 2005.

MELLO, J.B. de. Evolução do Ensino na Paraíba. João Pessoa- PB: Imprensa Oficial, 1956.

MIRANDA, I.V. Saber e Medo: métodos disciplinares e punitivos na Província da Parahyba do Norte (1822-1864). Monografia de Graduação em História, orientada por Cláudia Engler Cury. João Pessoa: DH/CCHLA/UFPB, 2009.

PARAÍBA. PROVÍNCIA. Discurso com que o prezidente da província da Paraíba do Norte, fez a abertura da sessão ordinária da Assembléa Provincial no mez de janeiro de 1837. Cidade da Paraíba, Typ. Paraibana, 1837. Disponível em: http://www.crl.edu/brazil. Acesso em: 22 de fevereiro de 2012.

PARAÍBA. PROVÍNCIA. Relatório apresentado a Assembléa Legislativa Provincial da Parahyba do Norte pelo excellentissimo presidente da Provincia, o bacharel João Antonio de Vasconcellos, em o $1^{\circ}$ de Agosto de 1849. Parahyba, Typ. de José Rodrigues da Costa, 1849. Disponível em: http://www.crl.edu/brazil. Acesso em: 24 de fevereiro de 2012.

PARAÍBA. PROVÍNCIA. Documentos Diversos sobre a instrução. João Pessoa: Arquivo público do estado da Paraíba, 2013.

PARAÍBA. PROVÍNCIA. LEIS E REGULAMENTOS DA INSTRUÇÃO DA PARAHYBA DO NORTE NO PERÍODO IMPERIAL. PINHEIRO, A. C.F.; CURY, C. E. (Orgs.). Coleção Documentos da educação brasileira [recurso eletrônico] - Dados 
eletrônicos- Brasília: Instituto Nacional de Estudos e Pesquisas Educacionais Anísio Teixeira, 2004.

PINHEIRO, A. C. F. Da era das cadeiras isoladas à era dos grupos escolares na Paraíba. Campinas, SP: Autores Associados; São Paulo: Universidade São Francisco, 2002.

- A discussão sobre a obrigatoriedade do ensino no século XIX e a contribuição de Manuel Tavares Cavalcanti nos anos de 1910 a1921. In: VIDAL, D. G.; SÁ, E. F. de; SILVA, V. L.G. da. Obrigatoriedade Escolar no Brasil. Cuiabá: Editora da Universidade Federal do Mato Grosso, 2013, p.171-188.

SAVIANI, D. História da escola pública no Brasil: questões para a pesquisa. In: LOMBARDI, J.C.; SAVIANI, D.; NASCIMENTOS, M.I. M. A escola pública no Brasil. História e historiografia. Campinas, SP: Autores Associados: HISTEDBR, 2005, p. 1- 29.

SOUZA, R. F. de. A organização pedagógica da escola primária no Brasil: do modo individual, mútuo, simultâneo, misto à escola graduada (1827-1893). In: Práticas escolares e processos educativos: currículo, disciplinas e instituições escolares (séculos XIX e XX). GONÇALVES NETO, W.; MIGUEL, M. E.B.; FERREIRA NETO, A. (Orgs.), Vitória, ES: EDUFES, 2011, p. 337- 367.

TEIXEIRA, Mariana Marques, Um olhar sobre a configuração da profissão docente na Parahyba Oitocentista (1822-1864). Monografia de Graduação em História, orientada por Cláudia Engler Cury. João Pessoa: DH/CCHLA/UFPB, 2009.

\section{Notas}

\footnotetext{
${ }^{1}$ Professora dos programas de pós-graduação em História e Educação da Universidade Federal da ParaíbaUFPB e líder do Grupo de Pesquisa em História da Educação do Nordeste Oitocentista (GHENO)/CNPq. Endereço eletrônico: claudiacury@ terra.com.br

${ }_{2}^{2}$ Mauricéia Ananias professora da graduação e do programa de pós- graduação da Universidade Federal da Paraíba- UFPB, vice-líder dos Grupos de Pesquisa em História da Educação do Nordeste Oitocentista (GHENO)/CNPq e História da Educação da Paraíba- HISTEDBR/PB / CNPq. Endereço eletrônico: mauricéia.ananias@gmail.com

3 Para esse trabalho utilizaremos os termos aulas, cadeiras e escolas indistintamente das suas possíveis diferenças. Todos eles deram a ideia da existência de escolas de primeiras letras considerando o contexto da Província da Parahyba do Norte nos anos iniciais do Império.

${ }^{4}$ Cf. Dentre tantos, os projetos desenvolvidos pelos grupos de pesquisa: "História, Sociedade e Educação no Brasil'- HISTEDBR; História da Educação no Nordeste Oitocentista- GHENO/UFPB; História da Escola Primária no Brasil: investigação em perspectiva comparada em âmbito nacional (1870 - 1930)/ UNESPCNPq; também dos programas de pós- graduação: A constituição da "forma escolar" no Brasil: produção, circulação e apropriação de modelos pedagógicos- PEPGE/ PUC-SP.

5 Cf. BRASIL. Lei de $1^{\circ}$ de outubro de 1828. Dá nova fórma às Camaras Municipais, marca suas attribuições, e o processo para a sua eleição, e dos Juizes de Paz, 1986.

${ }^{6}$ Cf. BRASIL. Lei ${ }^{\circ} 16$, de 12 de agosto de 1834. Faz algumas alterações e addições à Constituição política do Império, nos termos da Lei de 12 de outubro de 1832, 1986.

${ }^{7}$ Os relatórios de presidentes das províncias e dos ministros do império podem ser consultados na página do sítio eletrônico http://www.crl.edu/brazil. Acessado em 22 de fevereiro de 2012.

${ }^{8}$ Não foi encontrada referência à essa aula nos autores citados para a construção do quadro de aulas nesse primeiro período.

${ }^{9}$ Ver mais sobre a temática dos métodos empregados nas aulas de primeiras letras em Miranda (2009).

${ }^{10}$ Ver mais sobre a temática em Teixeira (2009).
}

Recebido em fevereiro-14

Aprovado em março-14 